International Journal of Modeling, Simulation,

and Scientific Computing

Vol. 5, No. 4 (2014) 1499001 (7 pages)

(C) World Scientific Publishing Company

DOI: 10.1142/S1793962314990013

\title{
Author Index \\ Volume 5 (2014)
}

Abdul-Ameer, A., see Whalley, R.

1 (2014) 1350017

Acharya, M., see Panda, B.

4 (2014) 1450021

Adlakha, N., see Jha, A.

2 (2014) 1350027

Agarwal, M. and Bhadauria, A. S., A stage structured model of malaria transmission and efficacy of mosquito larvicides in its control

4 (2014) 1450023

Allahyari, E., see Khansary, M. A.

1 (2014) 1350019

Azimi, S. S., Kalbasi, M. and Namazi, M. H., Effect of nanoparticle diameter on the forced convective heat transfer of nanofluid (water $+\mathrm{Al}_{2} \mathrm{O}_{3}$ ) in the fully developed laminar region

3 (2014) 1450008

Balamuralidhar, P., see Chakravarty, T.

S (2014) 1441006

1 (2014) 1350016

Baskaran, R., see Chandramohan, D.

3 (2014) 1450009

Bavio, J. and Marrón, B., Optimal capacity and buffer size estimation under generalized Markov fluids models and QoS parameters

S (2014) 1441002

S (2014) 1441007

4 (2014) 1450023

3 (2014) 1450009

S (2014) 1441006

Bhaumik, C., see Chakravarty, T.

Bin, X., Hongbo, S. and Tianyuan, X., An effective way to control congestion for RTI with hybrid architecture

1 (2014) 1340007

Boroomand, A., Tavakoli, M., Sloboda, R. and Usmani, N., Dynamical modeling and controllability analysis of a flexible needle in soft tissue

2 (2014) 1350031

Bruce Ralphin Rose, J. and Veni Grace, J., Performance analysis of lobed nozzle ejectors for high altitude simulation of rocket engines

Bui, T. Q., Tran, A. V. and Shah, A. A., Improved knowledge-based neural network (KBNN) model for predicting spring-back angles in metal sheet bending 
Chakravarty, T., Chowdhury, A., Ghose, A., Bhaumik, C. and Balamuralidhar, P., Statistical analysis of road-vehicle-driver interaction as an enabler to designing behavioral models

S (2014) 1441006

Chandramohan, D., Vengattaraman, T., Dhavachelvan, P., Baskaran, R. and Venkatachalapathy, V. S. K., FEWSS Framework to evaluate the service suitability and privacy in a distributed web service environment

1 (2014) 1350016

Chandy, A. J., see Rucki, C.

1 (2014) 1350014

Chen, J., Chen, K., Liu, R. and Liang, M., Analytical modeling of oxide thickness variation of metals under high temperature solid-particle erosion

3 (2014) 1450002

Chen, J., see Zhang, L.

Chen, K., see Chen, J.

Cheng, M., see Shang, Z.

2 (2014) 1350030

3 (2014) 1450002

2 (2014) 1350024

Chowdhury, A., see Chakravarty, T.

Cordeiro, M. N. D. S, see Vasumathi, V.

S (2014) 1441006

S (2014) 1441011

Dai, Y., see Wang, X.

Dhavachelvan, P., see Chandramohan, D.

3 (2014) 1450010

1 (2014) 1350016

Durdek, A., see Jensen, S. R.

S (2014) 1441003

Easters, D. J., The PACTUM model: Product analysis of cost and time using mathematics

Espinoza Ortiz, J. S., Belich Jr, H., Orlando, M. T. D. and

S (2014) 1441004 Lagos, R. E., Topological rearrangements and flow simulation of dry ordered foams

S (2014) 1441007

Fajin, J. L. C., see Vasumathi, V.

S (2014) 1441011

Fang, Z., see Liu, J.

4 (2014) 1450022

Fang, Z., see Liu, Y.

1 (2014) 1350015

Flå, T., see Jensen, S. R.

S (2014) 1441003

Frediani, L., see Jensen, S. R.

Für, A., Extended knowledge attributed petri nets

S (2014) 1441003

2 (2014) 1350028

García, H. L. and García, L. M., Feynman integrals and hypergeometric functions

S (2014) 1441001

García, L. M., see García, H. L.

S (2014) 1441001

Ghose, A., see Chakravarty, T.

S (2014) 1441006

Ghoshal, S. P., see Upadhyay, P.

4 (2014) 1450016

Hazi, G., see Toth, G.

He, S., see Liu, Y.

S (2014) 1441008

Hong, D., see Jiang, H.

1 (2014) 1350015

2 (2014) 1450001

Hongbo, S., see Bin, X.

1 (2014) 1340007

Hosseini, A., see Khansary, M. A.

1 (2014) 1350019 
Ibrahim, W. and Shanker, B., MHD boundary-layer flow and heat transfer over permeable plate with convective surface boundary condition

$1(2014) 1350021$

Jensen, S. R., Jusélius, J., Durdek, A., Flå, T., Wind, P. and Frediani, L., Linear scaling Coulomb interaction in the multiwavelet basis, a parallel implementation

S (2014) 1441003

Jha, A. and Adlakha, N., Finite element model to study the effect of exogenous buffer on calcium dynamics in dendritic spines

2 (2014) 1350027

Jha, N., High order accurate quintic nonpolynomial spline finite difference approximations for the numerical solution of non-linear two point boundary value problems

$1(2014) 1350018$

Jiang, H., Ma, Y., Hong, D. and Li, Z., A new metric for routing in military wireless network

2 (2014) 1450001

1 (2014) 1350019

3 (2014) 1450006

Ju, Z., see Sun, L.

Juanico, D. E., Epidemic cycle induced by intervention in a susceptibility-structured population

Jusélius, J., see Jensen, S. R.

S (2014) 1441012

$\mathbf{S}(2014) 1441003$

3 (2014) 1450008

Kanth, N., Ray, A. K. and Riti Mathematical model to investigate the effect of design and process parameters on nip width of supercalender

Kar, R., see Upadhyay, P.

Kashurnikov, V. and Krasavin, A., Quantum Monte-Carlo simulation of FeAs-based superconductors

Khansary, M. A., Joogh, F. K. Q., Hosseini, A., Safari, J., Allahyari, E., Zadeh, N. S. and Sani, A. H., Modeling drying of a coated paper

1 (2014) 1350019

Koltunov, M., see Tokar, M. Z.

Krasavin, A., see Kashurnikov, V.

$\mathbf{S}(2014) 1441005$

$\mathbf{S}(2014) 1441010$

Kuznetsov, S. A., see Zagubisalo, P. S.

S (2014) 1441009

S (2014) 1441007

2 (2014) 1350025

Langton, J. B., see Singal, J.

1 (2014) 1350022

Li, H., see Liu, J.

4 (2014) 1450022

Li, H., see Liu, Y.

1 (2014) 1350015

Li, H., see Zhao, M.

3 (2014) 1450007

Li, X. and Xiao, A., The improved Hagedorn wavepacket method for semiclassical Schrödinger equation

4 (2014) 1450013

Li, Z., see Jiang, H.

2 (2014) 1450001

Liang, M., see Chen, J.

3 (2014) 1450002 
Lin, J., see Sun, L.

3 (2014) 1450006

Liu, F. and Yang, M., Compositional colored Petri net approach to multiscale modeling for systems biology

$4(2014) 1450017$

Liu, J., Li, H., Fang, Z. and Liu, Y., Application of low-dimensional finite element method to fractional diffusion equation

4 (2014) 1450022

Liu, L., see Sun, L.

4 (2014) 1471001

Liu, R., see Chen, J.

3 (2014) 1450002

Liu, X., see Wang, J.

4 (2014) 1450014

Liu, Y., Li, H., He, S., Fang, Z. and Wang, J., A new characteristic expanded mixed method for Sobolev equation with convection term

1 (2014) 1350015

Liu, Y., see Liu, J.

Liu, Y., see Zhao, M.

4 (2014) 1450022

Liu, Z., see Sun, L.

Lou, J., see Shang, Z.

3 (2014) 1450007

3 (2014) 1450006

2 (2014) 1350024

Lu, D., see Sun, L.

3 (2014) 1450006

Lu, Y., see Wang, H.

1 (2014) 1330001

Ma, S., see Wang, P.

3 (2014) 1450003

Ma, Y., see Jiang, H.

2 (2014) 1450001

Mandal, D., see Upadhyay, P.

4 (2014) 1450016

Mao, S., see Sun, L.

3 (2014) 1450006

Marrón, B., see Bavio, J.

S (2014) 1441002

Misra, A. K., Lata, K. and Shukla, J. B., A mathematical model for the depletion of forestry resources due to population and population pressure augmented industrialization

1 (2014) 1350022

Mohanty, R. K., see Talwar, J.

2 (2014) 1350029

Muzy, A. and Zeigler, B. P., Specification of dynamic structure discrete event systems using single point encapsulated control functions

3 (2014) 1450012

3 (2014) 1450008

Ören, T., Coupling concepts for simulation: A systematic and comprehensive view and advantages with declarative models

Orlando, M. T. D., see Espinoza Ortiz, J. S.

2 (2014) 1430001

S (2014) 1441007

Panda, B., Acharya, M. and Panigrahi, D., Prediction of rice productivity in Kandhamal district of Orissa using simulation modeling

4 (2014) 1450021

Panigrahi, D., see Panda, B.

4 (2014) 1450021

Paulish, A. G., see Zagubisalo, P. S.

S (2014) 1441009 
Raczynski, S., Simulation and optimization in marketing:

Optimal control of consumer goodwill, price and investment

3 (2014) 1450004

Ray, A. K., see Kanth, N.

Riti, see Kanth, N.

Rucki, C. and Chandy, A. J., Towards FFT-based direct numerical simulations of turbulent flows on a GPU

4 (2014) 1450020

4 (2014) 1450020

1 (2014) 1350014

Safari, J., see Khansary, M. A.

1 (2014) 1350019

Sani, A. H., see Khansary, M. A.

1 (2014) 1350019

Schindler, R., see Singal, J.

2 (2014) 1350025

2 (2014) 1350026

Shang, Z., Cheng, M. and Lou, J., Parallelization of Lattice Boltzmann method using MPI domain decomposition technology for a drop impact on a wetted solid wall

2 (2014) 1350024

Shang, Z., High performance computing for flood simulation using Telemac based on hybrid MPI/OpenMP parallel programming

4 (2014) 1472001

Shanker, B., see Ibrahim, W.

Shen, Y., see Wang, P.

1 (2014) 1350021

3 (2014) 1450003

1 (2014) 1350022

Singal, J., Langton, J. B. and Schindler, R., Geant4 applications for modeling molecular transport in complex vacuum geometries

2 (2014) 1350025

Singh, H., Bhattacharya, A. and Batish, A., Finite element modeling and analysis of powder mixed electric discharge machining process for temperature distribution and volume removal considering multiple craters

3 (2014) 1450009

Sloboda, R., see Boroomand, A.

Sun, L. and Liu, L., Establishment and solution of the RNC

2 (2014) 1350031 flow network model

$4(2014) 1471001$

Sun, L., Lin, J., Ju, Z., Mao, S., Liu, Z. and Lu, D., Research of service selection algorithm for net-centric simulation task community

3 (2014) 1450006

Talwar, J. and Mohanty, R. K., A new modified group explicit iterative method for the numerical solution of time dependent viscous burgers' equation

$2(2014) 1350029$

Tang, L. and Wang, H., Flow latency analysis of component-based embedded software: Model and methodology

4 (2014) 1450018

Tavakoli, M., see Boroomand, A.

2 (2014) 1350031

Tianyuan, X., see Bin, X.

1 (2014) 1340007 
Tokar, M. Z. and Koltunov, M., "Shell" approach to modeling of impurity spreading from localized sources in plasma

S (2014) 1441005

Toth, G. and Hazi, G., Two-dimensional decaying turbulence in confined geometries

Tran, A. V., see Bui, T. Q.

S (2014) 1441008

2 (2014) 1350026

Upadhyay, P., Kar, R., Mandal, D. and Ghoshal, S. P., Opposition-based differential evolution for IIR system identification problem

4 (2014) 1450016

Usmani, N., see Boroomand, A.

Vasumathi, V., Fajin, J. L. C. and Cordeiro, M. N. D. S

2 (2014) 1350031 How reliable is the ReaxFF potential for describing the structure of alkanethiols on gold? A molecular dynamics study

Vengattaraman, T., see Chandramohan, D.

Veni Grace, J., see Bruce Ralphin Rose, J.

Venkatachalapathy, V. S. K., see Chandramohan, D.

Wang, H. and Lu, Y., The emerging challenge: The validity of computational organization model and methodology

Wang, H., see Tang, L.

Wang, J., Wu, Y. and Liu, X., Sliding mode controller design based on reaching law for hypersonic flight vehicle

Wang, J., see Liu, Y.

Wang, P., Ma, S. and Shen, Y., Performance study of feature descriptors for human detection on depth map

Wang, W., see Zhao, Z.

Wang, X., Zhu, W. and Dai, Y., Network simulation task partition method in heterogeneous computing environment

S (2014) 1441011

1 (2014) 1350016

4 (2014) 1450019

1 (2014) 1350016

1 (2014) 1330001

4 (2014) 1450018

4 (2014) 1450014

1 (2014) 1350015

3 (2014) 1450003

2 (2014) 1350023

3 (2014) 1450010

Whalley, R. and Abdul-Ameer, A., Ventilation system modeling and turbulence minimization

1 (2014) 1350017

S (2014) 1441003

Wu, Y., Yang, G. and Zhang, L., Mouse simulation in human-machine interface using kinect and 3 gear systems

$4(2014) 1450015$

Wu, Y., Zhao, W. and Zhu, J., A numerical approach for analyzing the transverse vibrations of an axially moving viscoelastic string

Wu, Y., see Wang, J.

3 (2014) 1450005

4 (2014) 1450014

Xiao, A., see Li, X.

4 (2014) 1450013

Yan, J., see Zhao, Z.

2 (2014) 1350023

Yang, G., see $\mathrm{Wu}, \mathrm{Y}$.

4 (2014) 1450015

Yang, M., see Liu, F.

4 (2014) 1450017

You, X., see Zhang, L.

2 (2014) 1350030 
Zadeh, N. S., see Khansary, M. A.

$1(2014) 1350019$

Zagubisalo, P. S., Paulish, A. G. and Kuznetsov, S. A., Simulation of thermal processes in metamaterial millimeter-wave to infrared converter for millimeter-wave imager

S (2014) 1441009

Zeigler, B. P., see Muzy, A.

3 (2014) 1450012

Zhang, L., You, X., Chen, J. and Zhang, L., Mathematical models for some problems in textile engineering and its corresponding discussions

2 (2014) 1350030

Zhang, L., see Wu, Y.

4 (2014) 1450015

Zhang, L., see Zhang, L.

2 (2014) 1350030

Zhao, M., Liu, Y. and Li, H., Fully discrete two-step mixed element method for the symmetric regularized long wave equation

3 (2014) 1450007

Zhao, W., see Wu, Y.

Zhao, Z., Wang, W. and Yan, J., Quantitative analysis of parameters' influence on the stability of coal roadway clamped by upper and lower soft rock with extra thickness

3 (2014) 1450005 Zhu, J., see $\mathrm{Wu}, \mathrm{Y}$.

2 (2014) 1350023

3 (2014) 1450005

Zhu, W., see Wang, X.

3 (2014) 1450010

Zong-Chang, Y., Complex matrix interpolation model of the S-transform for electric load movement forecast

3 (2014) 1450011 